\title{
Vitreous Chamber
}

National Cancer Institute

\section{Source}

National Cancer Institute. Vitreous Chamber. NCI Thesaurus. Code C33885.

The largest space within the eye which is bounded by the lens and the retina and filled with the gelatinous vitreous humor. 